\title{
Some Aspects of the Rheological Behaviour of Coal Water Slurries
}

\author{
Sunita Panda*, R.K. Swain \\ IGIT Sarang, India, 759146
}

\begin{abstract}
Initially coal-slurry fuels were based on coal-oil mixtures. Now the emphasis is largely on coal-water fuels. Since most of the studies have been done with coals available in the western countries having low ash content, an attempt has been made in this paper to study some aspects of the rheological behaviour of coal slurries prepared out of coals having high ash content. Crisis in the volatile oil markets experienced in the seventies have promoted renewed interest in coal-based fuel technologies. Coal-slurry fuels have emerged as viable technical alternatives for oil and gas in utility and industrial boilers. Despite current low prices and the abundance of oil, concerns over its long-term availability and price, as well as strategic considerations make coal-slurry technology attractive. In this paper an empirical relationship has been established among apparent viscosity and volume fraction of solids for coal having high ash content.
\end{abstract}

Keywords: Oil agglomeration, froth flotation, apparent viscosity, HAAKE rotational viscometer.

\section{Introduction}

Continued rise in oil prices, difficulties in supply of crude oil, increased fuel consumption, and the limited oil reserves in recent years have increased interest in the use of coal as coal water slurry. Coal is relatively cheaper, plentiful, and widely distributed across the globe. Further coal can be transported and stored very easily without much botheration. Therefore, many studies pertaining to coal water slurry (suspension of coal particles in water) as alternative fuel replacing petroleum oil in the liquid state have been carried out. Coal-water slurry has good liquidity and stability property. It has non-flammable and non-polluting properties. Initially coal-slurry fuels were based on coal-oil mixtures. Now the emphasis is largely on coal-water fuels. Some of the modern coal cleaning techniques e.g., oil agglomeration, froth flotation are very useful in this connection.

There are a number of incentives for potential users of coal slurry fuels and in particular for coal-water mixtures (CWMs). First CWM represents an assured supply of fuel at a price predictable into future years. Second, CWM is available in the near term; there are no substantial advances in technology needed to provide coal slurry fuels commercially. Third, there is minimal new equipment required to accommodate CWM in

${ }^{*}$ Corresponding author. Tel.: +919438406594

E-mail: sunita81panda@gmail.com

(C) 2014 International Association for Sharing Knowledge and Sustainability

DOI: $10.5383 /$ ijtee.08.02.006 the end-user's facility. Fourth, CWM is nearly as convenient to handle, store, and combust as is fuel oil. Several variants of CWM technology could be developed for different end-users in the future. One concept is to formulate slurry at the mine mouth in association with an integrated beneficiation process. This slurry fuel may be delivered to the end-user by any number of known conveyances such as barge, tank truck, and rail. Slurry fuel would then be stored on-site and used on demand in utility boilers, industrial boilers, and potentially for process heat needs or residential and commercial heating. An alternative approach is to formulate a low viscosity pre-slurry at the mine mouth and to pipeline it for a considerable distance, finishing up slurry formulation near the end-user's plant.

CWM technology also offers low risk of development than the other coal conversion technology through this development consist of mixture of water and coal, CWM is free from some of major problems of solid coal, such as powder dust and spontaneous combustion during storage and transportation. Unlike solid coal, moreover, CWM does not require large handling facilities (Hashimoto, 1999) [1].

The steps for the preparation of coal water mixture are shown in Fig. 1. It starts with washing of the coal and goes through different steps till it is transported to storage tanks. This mixture is passed through pipeline as coal water slurry to the end-user. 


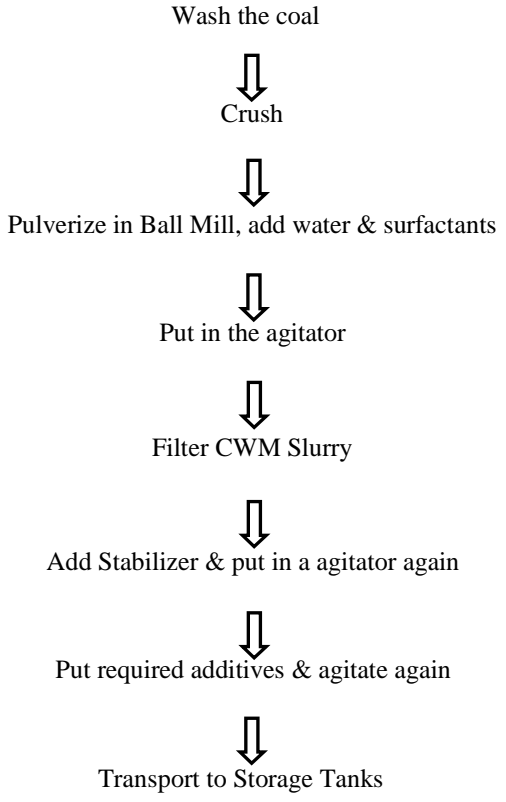

Fig. 1. Steps for the Preparation of Coal Water Mixture

\section{Literature Survey}

This section deals with literature review on rheology of coal water slurries. The rheology of coal and coal ash slurries has received attention in recent years because of widespread application in industry and academic interest. The focus of investigations has mostly been on viscosity of slurries and volume fraction of the solid.

Coal water slurry is environmental friendly as $\mathrm{NO}_{\mathrm{X}}, \mathrm{SO}_{\mathrm{X}}, \mathrm{CO}_{2}$ and suspended particulate matter reduction are reduced. Coal water slurry can be made from low grade coals by upgrading the coal which results the coal to have properties resembling the bituminous coal. Thus consequently CWM will have a good quality (Umar et al, 2006) [2].

CWM has several advantages, namely:

- $\quad$ Its treatment is similar to heavy oil.

- Will not cause spontaneous combustions, explosions.

- Could be used as fuel.

- Could be used with boilers similar with the boilers commonly used by heavy oil.

- If there is fuel switching from oil to coal, start-up time is shorter because it can use existing facilities with a slight adjustments to the burner.

Reddy et al. (1994) [3] studied the influence of particle size distribution on rheological properties of coal oil mixtures. The Rosin Rammer parameters and maximum packing fractions have been correlated with the viscosity of coal oil mixtures .It has been observed that coal oil mixtures with wider particle size distribution are less viscous.
Panda et al. (1996) [4] investigated the rheological behaviour of fly ash samples. They found that viscosity of the fly ash slurry shows Newtonian nature up to a solids concentration of $50 \%$ (by weight). Above this concentration the behaviour is Non-Newtonian. They used the pseudo-plastic model to estimate the head loss for the pipe flow and found that the transportation cost of fly ash slurry decreases drastically if it is transported at high concentrations instead of low concentrations.

Mishra et al. (2010) [5] investigated the rheological behaviour of coal-water slurry (CWS) using a HAAKE RV30 viscometer. They studied effect of solid concentration, ash content, $\mathrm{pH}$, and temperature on the rheology of CWS. The CWS was prepared on three coal samples with solids concentration varying from $50-55 \%$. They found that all the samples exhibited shear thinning behaviour with increase in viscosity at higher concentration and ash content. $\mathrm{pH}$ was found to have a strong influence on the viscosity with highest around pH-6 and lowest around $\mathrm{pH}-8$ for all slurry samples.

S. Panda (2014) [6] studied the rheological behaviour of coalwater slurry (CWS) using a HAAKE RV 30 viscometer to understand the properties of coal water mixture so that the same can be used as an alternative energy sources. It was found that the relation between yield stress and ash content is linear but deviates parallelly with the slurry concentration. Further it was concluded that the yield stress increases with the increase in ash content.

Coal water slurry should possess desirable rheological characteristic with regard to its stability, fluidity, handling, atomisability etc. Many rheological analyses has been carried out with this type of slurry.

\section{Experimental Setup}

\subsection{Material \& Methods}

Coal Type: Coal collected and used for experimentation work for this research work is having high ash content and low calorific value.

\subsection{HAAKE Rotational Viscometer}

A rheometer is a kind of viscometer that measures viscoelastic properties of materials beyond just Viscosity. A rheometer, therefore, measures material behaviour such as yield stress, kinetic properties, complex viscosity, modulus, creep, and recovery. Most rheometer model belongs to three specific categories. These are the rotational rheometer, the capillary rheometer, and the extensional rheometer. The most commonly used of these is the rotational rheometer, which is also called a stress/strain rheometer, followed by the capillary rheometer. The HAAKE Rotational Viscometer, Germany (model RV 30) used for this study was supplied by M/s HAAKE mess Technik, Germany. The experimental set up of the HAAKE Rotational Viscometer is shown in Fig. 2 below. 


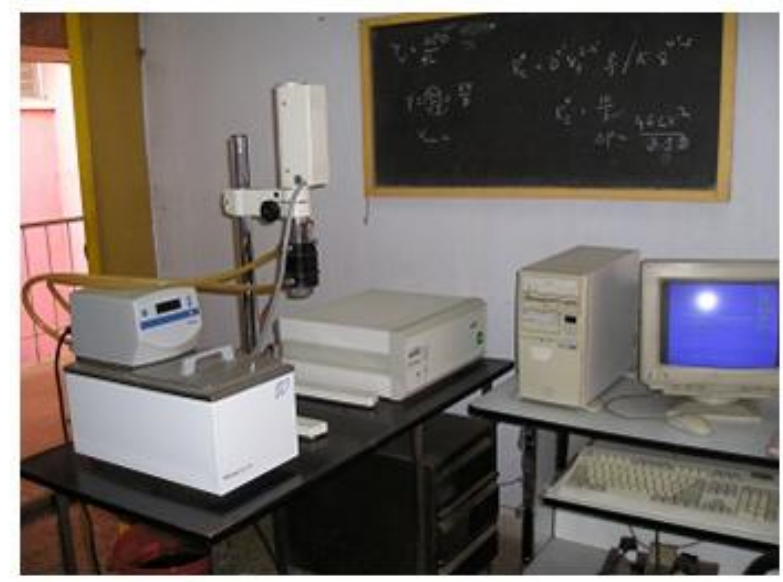

Fig. 2. Experimental Setup of HAAKE Rotational Viscometer

\subsection{Coal Slurry Preparation at Rheology Laboratory:}

In the laboratory a known amount of coal sample i.e. $30 \mathrm{~g}$ was taken in a beaker. To make slurry of $100 \mathrm{gm}$, required amount of water $(70 \mathrm{~g})$ of water was added to it. Then it was well stirred for 10 minutes for proper mixing and thus slurry of $30 \%$ concentration by weight was prepared. The same procedure was followed to prepare slurry of concentration $40 \%, 45 \%$, $50 \%, 55 \%$ and $60 \%$. Rheology of coal water slurry was studied at different concentration by using HAAKE Viscometer. The $\mathrm{pH}$ of the mixture was adjusted between $6 \& 7$ by adding $1.5 \%$ solution of lime by volume.

Following formula was used to calculate weight concentration: $\mathrm{Cw}=$ (weight of solid/weight of solid + weight of suspending medium)*100.

The volume fraction was calculated by:

$\varnothing=$ volume of solids/volume of solids + volume of suspending fluid.

$\varnothing=(\mathrm{Cwt} / \rho) /(\mathrm{Cwt} / \rho+(100-\mathrm{Cwt}) / \rho)$

Where $\varnothing=$ volume fraction

$\mathrm{P}=$ density of solid

Cwt=weight of solid

\section{Experimental Procedure}

A known amount of finely powdered coal sample is taken in a silica crucible and heated in a muffle furnace at $105-110^{\circ} \mathrm{C}$ for $1 \mathrm{hr}$. thereafter the crucible is taken out and cooled in a desiccators and weighted. The loss in weight shows the loss of moisture content from coal, then the moisture free coal when heated in a crucible fitted with cover in a muffle furnace at $950^{\circ} \mathrm{C}$ for $7 \mathrm{~min}$. The loss in weight shows the loss of volatile matter from coal, then the residue obtained after burning is kept in an open crucible at $750^{\circ} \mathrm{C}$ in a muffle furnace till a constant weight is obtained.

Coal obtained from different sources were crushed in a jaw-roll mill crusher, then the output from roll crusher which is from $10-15 \mathrm{~mm}$ is further grounded in a ball mill for 45 minutes to get the required particle size distribution.

\subsection{Experiment in HAAKE RV30 Viscometer}

For the rheological study, a suitable sensor system i.e. MV-1 was chosen of a given concentration, in order to provide accurate result. The rotor was inserted through temperature vessel from below into the measuring drive shaft and screwed tight. The cup to be used was filled up to the mark with this prepared slurry sample of $30 \%$ weight concentration and fitted into the temperature vessel from below and slowly pushed up as far as the stopper. The cup is secured using the union nut. Temperature was set to $30^{\circ} \mathrm{C}$ and shear stress was measured on varying shear rate ranging from $0-200(1 / \mathrm{s})$. The HAAKE Viscometer was operated for one minute and readings were taken. The data on viscosity and apparent viscosity were displayed on the computer screen and these data were transferred to a printer. Similar procedure was followed for $30 \%, 40 \%, 45 \%, 50 \%$, and $55 \%$ concentration. The viscosity and apparent viscosity are observed for coal water mixture at $30^{\circ}$.

The HAAKE RV30 Viscometer consists of Measuring Unit, Temperature vessel with circulator Sensor system and Software. The sensor system is designed to provide a specific range of shear rate and shear stress. For RV30, several types of sensor systems are available.

Namely:

$$
\begin{aligned}
& \Rightarrow \text { Coaxial cylinder sensor system } \\
& \Rightarrow \text { Cone \& plate sensor system } \\
& \Rightarrow \text { Disposable sensor system } \\
& \Rightarrow \text { High temperature sensor system }
\end{aligned}
$$

In this paper we have conducted the experiment by considering the coaxial sensor system. The coaxial sensor system consists of a cup and a rotor. The cup is inserted into the circular gap of the temperature vessel and supported by circular base which is screwed into the vessel. The rotor mixes the coal and water to make a mixture.

The rotovisco RV 30 can only be operated with the software rotation version 3.0. The computer is connected up via RS232C cable with RV 30 . The RV 30 requires certain minimum specification regarding the computer \& the peripheral equipment in order to function properly.

The minimum hardware requirements are:

- $\quad$ IBM/PC DOS computer with one disk \& hard drive.

- RAM of $640 \mathrm{~KB}$.

- Graphic adapter HGC, CGA, MCGA, EGA, VGA.

- Printer with electronic interface i.e. Epson - FX-80, FX-85, FX800.

- $\quad$ Operating system DOS 3.2 or higher.

\section{Result and Discussion}

Rheogram of coal water mixture have been prepared from the results obtained from HAAKE Viscometer. Tables 1 shows the relationship between apparent viscosity against weight concentration at $30^{\circ} \mathrm{C}$. The dependency of apparent viscosity with concentration of coal water slurry is shown in Fig. 3. This experimental result has been compared with Thomas [7] and Rutger [8]. It is observed that there is tremendous increase of apparent viscosity beyond concentration of $50 \%$. 
Table 2 shows the relationship between volume fraction and $1 /$ sqrt of apparent viscosity. The dependency of volume fraction and 1/sqrt of apparent viscosity is shown in Fig. 4. Here $\varnothing_{\mathrm{m}}$ is defined as the volume fraction of solids at which apparent viscosity is infinity. The value of $\emptyset_{\mathrm{m}}$ is determined by plotting a graph $1 / \sqrt{ }$ vs $\varnothing$ and intercept on $\varnothing$ axis gives $\emptyset_{\mathrm{m}}$. From Fig. $4, \emptyset_{\mathrm{m}}$ is found to be 0.5128 .

The relation between apparent viscosity and volume fraction is shown in Table 3. A log-log graph of apparent viscosity versus $\log \left(1-\varnothing / \varnothing_{\mathrm{m}}\right)$ is presented in Fig. 5. From Fig. 5, the following equation is proposed relating,$\varnothing$ and $\emptyset_{\mathrm{m}}$.

$\mu=C \times\left(1-\frac{\phi}{\phi_{m}}\right)^{-2.106}$

where $\mathrm{C}$ is a constant whose value is equal to 0.002 .

$\varnothing_{\mathrm{m}}=$ Maximum volumetric concentration

$=$ Apparent Viscosity and

$\varnothing=$ Volume concentration of solid

Table 1. Apparent Viscosity and True Viscosity at Different Concentration by Weight of Coal Water Mixture

\begin{tabular}{|l|l|l|l|}
\hline No. & $\begin{array}{l}\text { Wt. Conc. } \\
(\mathrm{Cw}, \%)\end{array}$ & True viscosity (pa) & $\begin{array}{l}\text { Apparent viscosity } \\
\text { (pas) }\end{array}$ \\
\hline 1 & 30 & 0.004676 & 0.004996 \\
\hline 2 & 40 & 0.008297 & 0.02941 \\
\hline 3 & 45 & 0.01914 & 0.02915 \\
\hline 4 & 50 & 0.06781 & 0.1363 \\
\hline 5 & 55 & 0.3155 & 0.5275 \\
\hline
\end{tabular}

Table 2. Relationship Between 1/Sqrt of Apparent Viscosity vs Volume Fraction

\begin{tabular}{|c|c|c|c|c|}
\hline No & $\begin{array}{c}\text { Wt Conc } \\
\left(\mathrm{C}_{\mathrm{w}}, \%\right)\end{array}$ & $\begin{array}{c}\text { Vol. } \\
\text { fraction }\end{array}$ & $\begin{array}{c}\text { Apparent } \\
\text { viscosity (pas) }\end{array}$ & $1 /$ sqrt \\
\hline 1 & 30 & 0.245 & 0.004996 & 14.1478 \\
\hline 2 & 40 & 0.336 & 0.02941 & 5.831127 \\
\hline 3 & 45 & 0.383 & 0.02915 & 5.857074 \\
\hline 4 & 50 & 0.431 & 0.1363 & 2.708645 \\
\hline 5 & 55 & 0.481 & 0.5275 & 1.376857 \\
\hline
\end{tabular}

Table 3. Relationship Between Apparent Viscosity vs Volume Fraction

\begin{tabular}{|c|c|c|c|c|c|c|}
\hline $\begin{array}{c}\mathrm{N} \\
\mathrm{o}\end{array}$ & $\begin{array}{c}\text { Wt. } \\
\text { Conc. } \\
\left(\mathrm{C}_{\mathrm{w}}, \%\right)\end{array}$ & $\begin{array}{c}\text { Vol. } \\
\text { Fraction }\end{array}$ & $\begin{array}{c}\text { Apparent } \\
\text { Viscosity } \\
(\mathrm{Pa})\end{array}$ & $\begin{array}{c}\text { Log } \\
\text { (Apparent } \\
\text { Viscosity) }\end{array}$ & $\begin{array}{c}\mathrm{Z}=(1- \\
\varnothing / Ø \mathrm{~m})\end{array}$ & $\begin{array}{c}\text { Log } \\
(\mathrm{Z})\end{array}$ \\
\hline 1 & 30 & 0.245 & 0.005 & -2.301 & 0.522 & -0.283 \\
\hline 2 & 40 & 0.336 & 0.029 & -1.532 & 0.345 & -0.462 \\
\hline 3 & 45 & 0.383 & 0.029 & -1.535 & 0.253 & -0.597 \\
\hline 4 & 50 & 0.431 & 0.136 & -0.866 & 0.159 & -0.799 \\
\hline 5 & 55 & 0.481 & 0.528 & -0.278 & 0.062 & -1.209 \\
\hline
\end{tabular}

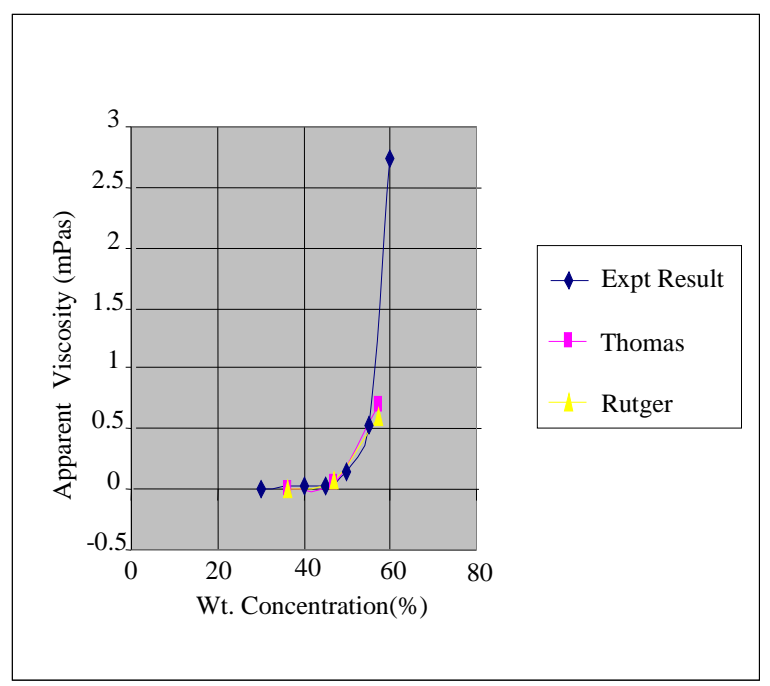

Figure 3. Apparent Viscosity vs Weight Concentration at $30^{\circ} \mathrm{C}$

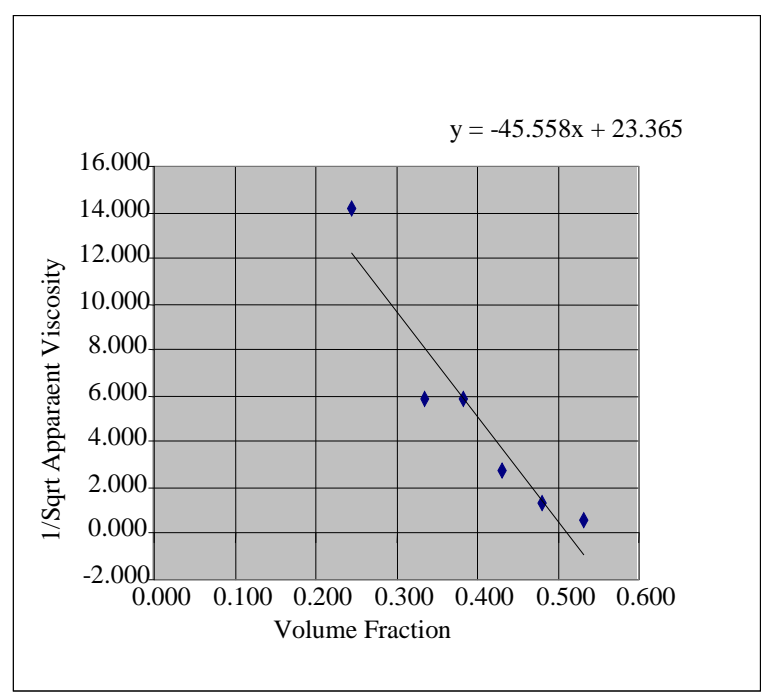

Figure 4. 1/Sqrt of Apparent Viscosity vs Volume Fraction

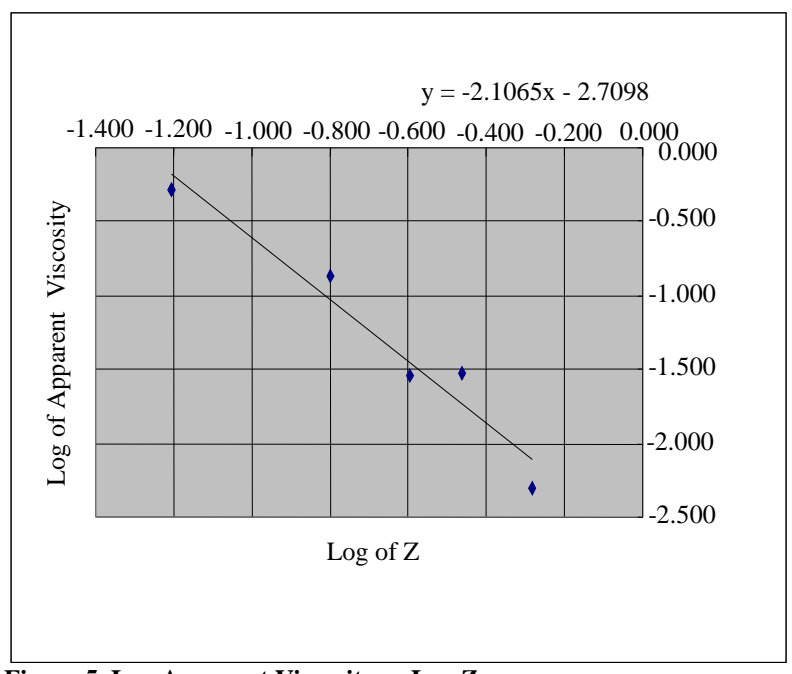

Figure 5. Log Apparent Viscosity vs $\log Z$ 


\section{Conclusion}

Following conclusion may be drawn from the above study.

- There is exponential increment of apparent viscosity with higher slurry concentration above $50 \%$.

- Apparent viscosity is a function of volume fraction of solids and may be related as:

$=0.002 *(1-\varnothing / \varnothing \mathrm{m})^{-2.106}$ for coals having high ash content.

- For replacement of dry coal burning in thermal power plants the CWM system has been suggested which is environmental friendly. Coal can be obtained from river ground and mix with water to make CWM and can be transported through pipeline to the user site. An equation predicting the viscosity has been obtained $=0.002 *(1-\varnothing / \varnothing \mathrm{m})^{-2.106}$.

- The coal water mixture considered for experiment as a replacement of fuel oil have a $\varnothing \mathrm{m}$ value of 0.55 suggesting that it should further be beneficiated to reduce its ash content.

The above characterization of coal water mix will go a long way in its usage as an alternate source of fuel considering the rheological studies will be helpful in designing pipelines for transportation of slurry with optimum solid concentration which has become an attractive mode of transportation.

\section{References}

[1] Hashimoto, N., "Coal Water Mixture Preparation", Coal Preparation, vol. 21, pp. 3-22, 1999.
[2] Umar, D. F., Daulay, B., Usui, H. and Komoda, Y., "Preparation of Carbonized Biomass Water Mixture and Upgraded Coal Water Mixture", Journal of Chemical Engineering of Japan, vol. 39, no. 11, pp. 1206-1212, 2006, DOI: $10.1252 /$ jcej.39.1206.

[3] Reddy, G.V., Mohapatra, S. K. and Sinha, R. K. "Rheological properties of coal oil mixtures: Influence of coal particle size distribution", Institution Of Engineers India, Journal Chemical Engineering Division, vol. 75, pp. 25-28, 1994.

[4] Panda, D., Parida, A., Murthy, J. S. and Mitra, A. K., "Transportation of coarse coal in a fine medium", international journal of multiphase flow", vol. 20, no. 1, pp. 171-177, 1994, DOI: 10.1016/0301-9322(94)900132 .

[5] Mishra, S. K., Senapati, P. K., and Panda, D., "Rheological Behavior of Coal-Water Slurry", Energy Sources, vol. 24, no. 2, pp. 159-167, 2002, DOI: $10.1080 / 00908310252774471$.

[6] Panda, S., "Coal Water Slurry As a Substitute for Fuel Oil in India", International Journal of Engineering Research \& Technology, vol. 3, no. 4, pp. 1111-1115, 2014.

[7] Thomas, D. G., "Transport characteristics of suspension: VIII. A note on the viscosity of Newtonian suspensions of uniform spherical particles", Journal of Colloid Science, vol. 20, no. 3, pp. 267-277, 1965, DOI: 10.1016/0095-8522(65)90016-4.

[8] Rutgers, R., "Packing of spheres", Nature, vol. 193, pp. 465-466, 1962, DOI: 10.1038/193465a0. 